\title{
WORK FORCE Medical students and end-of-life decisions: the influence of religion
}

\author{
Authors: Suzie Pomfret, ${ }^{\mathrm{A}}$ Shaya Mufti ${ }^{\mathrm{B}}$ and Clive Seale ${ }^{\mathrm{C}}$
}

The objective of this study was to see if medical students' attitudes about medically assisted dying were influenced by their religious background and current beliefs. A cohort study was conducted using a self-completion study questionnaire in a large UK medical school. In total, 400 out of 505 questionnaires were completed (79\%). The study population's characteristics are summarised as follows: mean age 22.7 years (range 18-44); $68.5 \%$ believe in god, $31.5 \%$ have no belief in god; religious background: Christian 45\%, Hindu 16.5\%, Muslim $22 \%$, Other $10 \%$ and None $7 \%$. The majority of students did not agree with euthanasia and physician-assisted suicide in the study scenario. Those who had a belief in god were more likely to disagree with actions that hasten death. The findings show this was particularly the case with students from a Muslim background. Gender was not related to overall agreement with actions that hasten death; being older, a finalist and a graduate were weakly associated with a greater likelihood of agreeing with such acts. This is an important issue which warrants further enquiry. The demographics of the UK medical population continue to shift, containing a higher proportion of people from Asia and with Asian British backgrounds than the general population. This study provides us with a basis for further exploration of the potential for disparity between the opinions of the UK population and those of medical workers and trainees, and how that might inform decisions about patient care at the end of life.

KEYWORDS: End-of-life, religion, euthanasia

\section{Introduction}

Euthanasia has been defined as a 'deliberate intervention undertaken with the express intention of ending a life to relieve intractable suffering,. The subject of euthanasia and physicianassisted suicide (PAS) (the intentional and wilful ending of one's own life with the assistance of a physician, with a view to reducing suffering and ensuring a patient experiences a 'good death'), is a multifactorial, contentious issue which has been debated

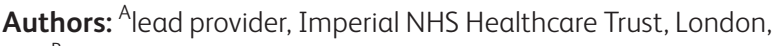
UK; ${ }^{B}$ lead provider, Imperial NHS Healthcare Trust, London, UK;

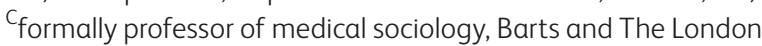
School of Medicine and Dentistry, London, UK for centuries. Opinions continue to remain polarised among the public, professional and religious bodies in many countries, and the issue remains on the public agenda through a series of high profile legal challenges to the existing law in the UK.

In the UK the influence of religious belief on doctors' decision making and the advice they give to their patients was brought into contention in 2011 with the case of Dr Richard Scott, a Christian GP, who was accused of 'pushing' religion on to his patients and subsequently reprimanded by the General Medical Council $(\mathrm{GMC}){ }^{2} \mathrm{GMC}$ guidance to medical professionals about this issue states:

You must not express to your patients your personal beliefs, including political, religious or moral beliefs, in ways that exploit their vulnerability or that are likely to cause them distress. ${ }^{3}$

The medical population of the UK contains a higher proportion of people from ethnic minority backgrounds than the general UK population, especially Asian and Asian British doctors whose levels of religious belief and practice tend to be somewhat higher than those of white, European doctors. ${ }^{4}$ Doctors of Buddhist, Hindu, Jewish and Muslim faiths are more common in the UK medical population when compared with the UK general public, who are more likely to be of Christian faith. Even within different fields of medicine there are variations and measurable trends in the religious and ethnic makeup of doctors.

Palliative care physicians who frequently deal with end-of-life decisions are more likely to be Christian, white and report being 'very or extremely religious' than doctors in other specialties, while those specialties involving care of elderly patients contain more Asian doctors, and, linked to this, more Hindu or Muslim doctors. ${ }^{4}$ In view of this, the degree to which the religious views of doctors influence medical decision making in ethically controversial areas deserves examination.

A survey of UK doctors asked whether a person with an incurable and painful disease from which they will die, should be allowed by law to end their life. The results demonstrated that roughly one-third agreed while almost two-thirds disagreed. Additionally, doctors working in palliative care were more likely to disagree with assisted dying. ${ }^{5}$

The current policy of the British Medical Association (BMA) on euthanasia and PAS is unequivocal: it should remain illegal in the UK. However, it recognises patients' right to refuse life-prolonging treatment. ${ }^{6}$ In contrast, $82 \%$ of the British public would support a law change to allow people with a terminal illness and unbearable suffering to receive medical assistance to die. ${ }^{7}$ 
As more countries such as the Netherlands, Belgium,

Switzerland, Luxembourg, Canada and Columbia, and the states of Oregon, Washington, Vermont and California in the USA, have decriminalised assisted dying in some form or other, ${ }^{8}$ pressure is mounting within the UK to follow suit. It is therefore important to gauge the opinion of current and future UK medical professionals on this issue (the Royal College of Physicians has carried out surveys of its members in 2006 and 2014 - see Porter et al in this issue.).

A systematic review of studies describing the attitudes of UK doctors towards euthanasia and PAS over a 20-year period has shown that most UK doctors oppose the introduction of both active voluntary euthanasia (AVE) and PAS in the majority of studies. ${ }^{8}$ Seale's study compared medical attitudes directly with those of the general public, showing that the two groups differ significantly, with doctors being largely opposed to, and the general public being largely in support of, a change in the law to allow assisted dying. ${ }^{10}$ Opposition to assisted dying by doctors and the general public is associated with a strong religious belief. ${ }^{9,10}$

Studies of the views of medical students have been carried out in a number of countries, and these are important in gauging the likely attitudes of future generations of doctors. Marini et al showed that Swiss medical students were more in favour of PAS and euthanasia than practising oncologists and, in particular, palliative care physicians. ${ }^{11}$ A study in 1992 showed that $77 \%$ of third and fourth year medical students at the University of Miami felt that there was a moral justification to assist in a patient's death. ${ }^{12}$ In spite of this, only a minority said that they would be willing to administer medications to cause a respiratory/cardiac depression or a cardiac arrest (6\% and 1\% respectively). In 1999 , another study found that less than half of 96 respondents (3rd year medical students from Atlanta, USA) thought that assisting a patient to die was morally justified ${ }^{13}$ and in 2006 a study showed that more than a third of the 5th year German students thought that PAS in certain situations was ethically acceptable. ${ }^{14}$

Most religious teachings emphasise the importance of the sanctity of life. Medical students with strong religious beliefs are more likely to oppose euthanasia and PAS; two small studies of students in Holland ${ }^{15}$ and New Mexico ${ }^{16}$ respectively support this, with a larger Norwegian study which included medical students in a multiprofession survey, finding that Christian students were less supportive of both euthanasia and PAS than students of another faith or without definable faith. ${ }^{17}$ A Puerto Rican study of medical students, by contrast, found religious affiliation to be unrelated to opposition to euthanasia or PAS. ${ }^{18}$ In the UK the views of medical students remain relatively unstudied, the exception being a survey of 162 students in Glasgow reporting opinions on withdrawal of treatment which did not, however, investigate the influence of religious views. ${ }^{19}$ In view of the dearth of UK studies of medical student attitudes and evidence about the changing ethnic and religious composition of the UK medical population, our study aims to begin to explore the influence of religion on British medical students' views on euthanasia and PAS.

\section{Aims}

This study examines British medical students' opinions on euthanasia and PAS. It elucidates the influence of students' religious background, age, gender, year of study and strength of religious belief on these issues.
This study draws on some hypotheses, based on earlier studies.

1 Male medical students will be more supportive of euthanasia and PAS than female medical students. ${ }^{15-17}$

2 Support for euthanasia and PAS will increase with age..$^{20,21}$

3 Support for euthanasia and PAS will increase from the first year of study to the final (5th) year. ${ }^{20}$

4 Religious background and strength of religious belief will influence a person's attitude to euthanasia and PAS. ${ }^{16-18}$

\section{Method}

A survey, using a self-completion questionnaire, of first and final year medical students at Barts and the London School of Medicine and Dentistry (located in the east of London) was conducted. Ethical approval for the study was granted by the university ethics committee (Queen Mary, University of London). Questionnaires were handed out at the start of a lecture and collected at the end by one of the authors. Of the 505 questionnaires handed out, 400 (79\%) were completed. The questionnaire was introduced with a short description of the study, confirmation of confidentiality and anonymity, and assurances that there was no compulsion to take part. Consent was assumed by the completion of the questionnaire.

Characteristics of respondents (age, year group, graduate status, religious background (ie the religion the student was brought up with) and current religious belief (atheist, agnostic or theist) were collected via the questionnaire. In addition, the questionnaire showed five scenarios based on a summarised case and the subsequent actions of a doctor (see Table 1 and Appendix 1). Respondents were asked to score their agreement/disagreement with these actions using a Likert scale. The last question was a simple yes or no answer to the question of whether they thought that they personally could administer a lethal injection in a similar situation.

\section{Analysis}

Data were analysed using SPSS. Univariate statistics describe the responses to individual attitude questions (Table 1). Attitude items one to five were then added together to produce a scale (called 'Agree') ranging from five (meaning the respondent strongly disagreed with all of the items) to 25 (meaning the respondent strongly agreed with all of the items). The mean of this scale was $14.5(S D=3.9)$ and its skewness was $0.10(S D=0.12)$. Each contributing item correlated positively and significantly $(p<0.005)$ with the overall scale. The bivariate relationships between independent variables and the agreement scale (the dependent variable) are shown in Table 2.

The sample of participants consisted of a higher proportion of people with Hindu and Muslim backgrounds than one would expect from national statistics on the ethnic origins and religious faiths of UK doctors. These show that $12 \%$ of the UK medical population in 2008 were 'Asian' (NHS Information centre 2010). ${ }^{20}$ A 2008 survey of a nationally representative sample of UK doctors found $52 \%$ reporting that they had a Christian faith, 7.5\% Hindu and 5.8\% Muslim faith. ${ }^{4}$ The relatively high proportion of these students indicating that they are from Hindu and Muslim backgrounds reflects the particular characteristics of the participating hospitals, Barts and the London School of Medicine, which are located in the East End of London, an area with a higher representation of people from Hindu and Muslim 
Table 1. Attitudes to ending life: levels of agreement with action described $(N=400)$

\section{Strongly disagree \\ Disagree \\ Neither agree nor disagree \\ Agree \\ Strongly agree \\ Mean*}

1. Mrs X is medically well. She is deemed competent. She wishes for the ventilator to be withdrawn. The consulting physician switches off the ventilator.

$9 \%$

$20 \%$

$13 \%$

$44 \%$

$14 \%$

2. Mrs X is medically well. She is deemed competent. She wishes to die. She asks her consulting physician to help her die. The physician agrees to assist death by personally, slowly, increasing her morphine dose.
$21 \%$
$36 \%$
$15 \%$
$23 \%$
$5 \%$

3. Mrs X develops a chest infection. She falls into septic shock and eventually into a coma. The doctors on ICU agree that she is brain dead and consult the family to switch off the ventilator. The consulting physician switches off the ventilator.
$3 \%$
$6 \%$
$11 \%$
$51 \%$
$29 \%$

4. Mrs X is medically well. She is deemed competent. She wishes to die. She asks her consulting physician to help her die. The physician agrees to assist death personally administering a lethal injection of potassium chloride.
$36 \%$
$35 \%$
$13 \%$
$13 \%$
$3 \%$

5. Mrs X is medically well. She has severe cognitive impairment as a result of her disease. She wishes for the ventilator to be withdrawn. The consulting physician switches off the ventilator.
$16 \%$
$38 \%$
$23 \%$
$20 \%$
$3 \%$
2.56
Yes
No

6. Do you think you, as a doctor, could administer a lethal injection (eg potassium chloride) to a competent patient, like Mrs X, who wishes to die? (Please again assume that such an action is legal.)**

$24 \%$

$76 \%$

*5 means high agreement; 1 means high disagreement

**Three respondents did not answer

communities than the national average. ${ }^{22}$ Students from a Muslim family background were particularly likely to indicate that they had a current belief in a god. People from a Christian background were considerably less likely to say this.

Table 1 shows that support for the actions in question two and four is lowest. These are both actions which involve introducing a substance into the body with the intention of causing death. Question four, which has the lowest support, in particular deals with the administration of a potassium chloride injection which has no therapeutic purpose and whose sole purpose would therefore be to bring about death. Lack of support for this action is also evident in the answers to question six. Support is at its highest for the action described in question three, which involves withdrawing ventilation, an action that is legal in the UK.

The results in Table 2 show that gender is not related to overall agreement with actions that hasten death. Being older, a finalist and a graduate are weakly associated with a greater likelihood of agreeing with such actions. Being a non-believer is more strongly associated. People from Muslim family backgrounds are particularly likely to disagree with actions that hasten death.

\section{Discussion}

This study has shown, first, that in this cohort there is an overall opposition to acts which involve hastening death, excluding withdrawal of ventilation. It seems likely, given these results, that the majority of these medical students may therefore oppose any future change in the law in the UK which would legalise medically assisted dying. Second, Muslim students are significantly more likely than students who indicate they belong to other religious groups, to oppose acts which hasten death and this difference holds even when students who do not have a religious belief are excluded from the analysis. Finally, older students, finalists and graduate-entry students are slightly more likely than other students to agree with acts which hasten death.

Despite the fact that respondents were told to assume that the actions of the doctor in the scenarios were legal, the results demonstrate that students still make a clear distinction between letting die and killing. This is in keeping with St Thomas Aquinas' doctrine of double effect which states that an action with potential harmful effects is justifiable if the nature of the act is itself good or at least morally neutral, if the agent intends the good effect and if the good effect outweighs the bad under circumstances sufficiently grave to justify causing the bad effect. ${ }^{23}$ The results also demonstrate that the situation of the patient and the mode of hastening death are important to the students. For example, there was greater opposition to the use of a lethal injection of potassium chloride to hasten death than using an overdose of morphine.

All the scenarios concern a patient with the same condition, and consequently we cannot extrapolate the results to all patients. However, this condition was chosen because it frequently generates support for PAS and euthanasia, and withdrawal of ventilation does often occur. Further research could consider other situations and patients with other conditions.

The difference of opinion between Muslim students and other theist and atheist students shown in the results is relevant as the demographics of the UK medical population continues to shift. Seale demonstrated that compared with the general 


\begin{tabular}{|c|c|c|c|c|}
\hline & $N$ & Mean $(95 \% \mathrm{CI})$ & SD & p-value \\
\hline \multicolumn{5}{|l|}{ Gender } \\
\hline Male & 161 & 14.9 & 4.2 & $0.124^{* *}$ \\
\hline Female & 239 & 14.2 & 3.7 & \\
\hline \multicolumn{5}{|l|}{ Year } \\
\hline First year & 232 & 14.1 & 3.9 & $0.009^{* *}$ \\
\hline Final year & 168 & 15.1 & 3.9 & \\
\hline \multicolumn{5}{|l|}{ Graduate } \\
\hline $\begin{array}{l}\text { Graduate } \\
\text { entry }\end{array}$ & 187 & 14.8 & 3.9 & $0.009^{* *}$ \\
\hline $\begin{array}{l}\text { Non } \\
\text { graduate } \\
\text { entry }\end{array}$ & 213 & 14.2 & 3.9 & \\
\hline \multicolumn{5}{|l|}{ Belief } \\
\hline Belief in god & 274 & 13.8 & 3.9 & $<0.0005^{* *}$ \\
\hline $\begin{array}{l}\text { No belief in } \\
\text { god }\end{array}$ & 126 & 16.2 & 3.5 & \\
\hline \multicolumn{5}{|l|}{ Background } \\
\hline Christian & 179 & $15.4(14.8-16.0)$ & 3.9 & $\begin{array}{l}F=12.7 \\
p<0.0005^{* *}\end{array}$ \\
\hline Hindu & 66 & $14.6(13.7-15.6)$ & 3.7 & \\
\hline Muslim & 88 & $12.1(11.4-12.9)$ & 3.5 & \\
\hline Other & 33 & $14.7(13.5-16.0)$ & 3.5 & \\
\hline None & 34 & $15.7(14.5-17.0)$ & 3.5 & \\
\hline \multicolumn{5}{|l|}{ Age } \\
\hline & NA & NA & NA & $\begin{array}{l}0.015\left(r^{2}=0.122\right. \\
\text { for correlation of } \\
\text { age with 'agree') }\end{array}$ \\
\hline
\end{tabular}

population they serve, the UK medical population contains more doctors from Asian and Asian British backgrounds, and that some other ethnic minorities are also more highly represented in the medical workforce than in the general population. ${ }^{4}$ Figures describing the ethnic composition of the NHS medical workforce suggest that this difference has increased over the past 20 years or so. In $2010,{ }^{24} 59.0 \%$ of doctors working in hospital specialities who stated their ethnicity described themselves as 'white'; the same figure from 1991, nearly 20 years previously, was $72.0 \% .{ }^{25}$ In 2010 , Asian and Asian British doctors constituted $28.5 \%$ of this workforce, black and black British 3.6\%, Chinese $2.2 \%$, and another ethnicity $6.6 \%$. The same figures from 1991 are $12.4 \%$ Asian, $5.0 \%$ black, 1.2\% Chinese and $9.5 \%$ another ethnicity. Seale also found that the type of religion followed by doctors differs somewhat from the general population, particularly in relation to the Hindu and Islamic religion. ${ }^{4}$ It seems likely that as the numbers of Asian doctors has risen, so also will have the proportion of Muslim and Hindu doctors.
It is known that the proportion of Muslims in the medical population is greater than the proportion in the general population, and our study shows Muslim medical students have views that are particularly opposed to allowing euthanasia or physician-assisted suicide; the legalisation of which, as we showed in our earlier review of literature, attracts widespread support within the general UK population, although not in the medical population. We must therefore consider how the potentially increasing disparity of views between future doctors and the population they serve may affect patient care.

Although the respondents in this survey were reporting on hypothetical situations, there is evidence to suggest that religious belief, or the lack of it, is associated with the actual clinical decisions that doctors make in end-of-life care. ${ }^{4}$ This contrasts with the reported view of some medical students that 'Religious beliefs do not influence or have an impact on patient care. ${ }^{26}$ It is, of course, possible that it is difficult to become consciously aware of such influences on clinical decision making. Less difficult to bring to conscious awareness, however, is the matter of whether to talk to patients about one's own religious beliefs. Here, the UK GMC is quite clear in their advice:

Our guidance, which all doctors must follow, is clear; doctors should not normally discuss their personal beliefs with patients unless those beliefs are directly relevant to patient care. (Niall Dickinson, GMC chief executive) ${ }^{27}$

Patients can sometimes ask directly about our faith, especially in discussions about end-of-life issues. The guidance offered by the GMC gives examples of where a professional's beliefs may come into conflict with certain clinical practices (such as abortion) and what one should then do. However, there is no guidance on this subject that relates to end of life issues. Should there be a change in the law in the UK on euthanasia and PAS, careful thought will need to be given to guidance and support to doctors concerned with these matters. This is especially important in view of evidence that physicians, where these practices are legal (Netherlands and Belgium), have reported mixed emotions, with more than $80 \%$ stating they could envision becoming involved in a case and an equally high number reporting that they dreaded the emotional turmoil involved. ${ }^{8}$

Religious belief affects many life decisions, both personal and professional, and it may be naive to imagine that a person's religion will not affect their clinical decisions. Our findings suggest an urgent need for bodies like the GMC to consider more fully how doctors can manage the personal conflicts and dilemmas that are likely to occur when their religious beliefs differ from those of their patients in end-of-life care.

\section{Strengths and limitations}

The study had a $79 \%$ respondent rate (400 out of 505 questionnaires), with $22 \%$ of the respondents stating that they were from a Muslim background. Of these, $99 \%$ were still believers in a god. The study was limited to one medical school in the UK, albeit one with an ethnically diverse student body. The study questionnaire was limited to one case study concerning motor neurone disease, but this disease was used as it is a commonly cited disease in debates on these subjects. Further exploration would be valuable into the views of believers from other religions towards assisted dying, PAS and euthanasia, as well as exploring the views of those with no religious belief. 
This study, and the others referenced here, are all relatively small and should be the beginning of a larger exploration of views in this area. As part of future research, it would be useful to examine the influence, for example, that geographical location has on attitudes towards assisted dying. Is there a disparity between beliefs between and within countries, or even an urban vs rural divide?

\section{Conclusion}

This study found that within this cohort in east London, medical students who stated they had an active religious belief, and in particular students of Muslim faith, were likely to disagree with actions that hasten death. Gender was not found to be associated with a particular opinion on this subject; however, being older, a final year or a graduate were weakly associated with a greater likelihood of agreeing with such actions. The findings in this paper are especially relevant when we consider the changing demographics of the UK medical population, which contains a higher proportion of people from Asia and Asian backgrounds than the general population. There is a need for research on a wider scale into this issue, exploring the broad range of factors that can influence attitudes on medically assisted dying, including cultural considerations more widely. This article can perhaps aim to serve as a starting point to a valuable debate that has not been fully addressed in the UK. Any debate would need to be inclusive and involve all religions and secular groups who represent the views of the population and all those who will at some point rely on end-of-life care in this country.

\section{Supplementary material}

Additional supplementary material may be found in the online version of this article at http://futurehospital.rcpjournal.org S1 - Questionnaire

\section{References}

1 Harris NM. The euthanasia debate. J R Army Med Corps 2001;147:367-70.

2 Doctors can be Christians too. www.telegraph.co.uk/news/ religion/8528371/Doctors-can-be-Christians-too.html [Accessed 8 July 2011].

3 General Medical Council. Personal belief and medical practice: guidance for doctors. General Medical Council (UK), 2013. www. gmc-uk.org/guidance/ethical_guidance/personal_beliefs.asp [Accessed 8 July 2011].

4 Seale C. The role of doctors' religious faith and ethnicity in taking ethically controversial decisions during end-of-life care. J Med Ethics 2010;36:677-82.

5 Nordqvist C. Euthanasia and assisted suicide. Medical News Network Knowledge Centre, 2016. www.medicalnewstoday.com/ articles/182951.php [Accessed 16 August 2016].

6 British Medical Association. End of life decisions: Views of the BMA. London: BMA, 2009.

7 National Opinion Poll Survey 420936. Choices. NOP, 2004.

8 Zuger A. Update on euthanasia and physician-assisted suicide. New England Journal of Medicine Journal Watch, 2016. www. jwatch.org/na41778/2016/07/14/update-euthanasia-andphysician-assisted-suicide [Accessed 16 August 2016].

9 McCormack R, Clifford M, Conroy M. Attitudes of UK doctors towards euthanasia and physician-assisted suicide: A systematic literature review. Palliat Med 2012;26:23-33.
10 Seale C. Legalisation of euthanasia or physician-assisted suicide: survey of doctors' attitudes. Palliat Med 2009;23:205-12.

11 Marini MC, Neuenschwander H, Stiefel F. Attitudes toward euthanasia and physician assisted suicide: a survey among medical students, oncology clinicians, and palliative care specialists. Palliat Support Care 2006;4:251-5.

12 Caralis PV, Hammond JS. Attitudes of medical students, housestaff, and faculty physicians toward euthanasia and termination of lifesustaining treatment. Crit Care Med 1992;20:683-90.

13 Hayes RP, Stoudemire AS, Kinlaw K, Dell ML, Loomis A. Changing attitudes about end-of-life decision making of medical students during third-year clinical clerkships. Psychosomatics 1999:40:20511

14 Schildmann J, Herrmann E, Burchardi N, Schwantes U, Vollmann J. Physician assisted suicide: knowledge and views of fifth-year medical students in Germany. Death Stud 2006;30:29-39.

15 Muller MT, Onwuteaka-Philipsen BD, Kriegsman DM, van der Wal G. Voluntary active euthanasia and doctor-assisted suicide: knowledge and attitudes of Dutch medical students. Med Educ 1996;30:428-33.

16 Warner TD, Roberts LW, Smithpeter M et al. Uncertainty and oppo sition of medical students toward assisted death practices. J Pain Symptom Manage 2001;22:657-67.

17 Schioldborg P. Students' attitudes toward active euthanasia, assisted suicide and proposed amendments to the penal code. Tidsskr Nor Laegeforen 2000;120:2283-8.

18 Ramírez-Rivera J, Cruz J, Jaume-Anselmi F. Euthanasia, assisted suicide and end-of-life care: attitudes of students, residents and attending physicians. P R Health Sci J 2006;25:325-9.

19 Goldie J, Schwartz L, Morrison J. Students' attitudes and potential behaviour to a competent patient's request for withdrawal of treatment as they pass through a modern medical curriculum. J Med Ethics 2004;30:371-6.

20 Gruber PC, Gomersall CD, Joynt GM et al. Changes in medical students' attitudes towards end-of-life decisions across different years of medical training. J Gen Intern Med 2008;23:1608-14.

21 Radulovic S, Mojsilovic S. Attitudes of oncologists, family doctors, medical students and lawyers to euthanasia. Support Care Cancer 1998:6:410-5.

22 Office for National Statistics. Religion in England and Wales 2011. ONS, 2012.

23 McIntyre Alison. Doctrine of double effect. Stanford encyclopedia of philosophy, 2009. http://plato.stanford.edu/entries/doubleeffect/ [Accessed 27 July 2011].

24 Department of Health. Medical and dental workforce statistics: historical data from 1975 to 2002. DH, 2007. www.dh.gov.uk/ en/Publicationsandstatistics/Statistics/StatisticalWorkAreas/ Statisticalworkforce/DH_4101839. [Accessed 27 July 2011].

25 NHS information Centre. NHS Staff 2000-2010 (Medical and Dental). The Health and Social Care Information Centre, 2011. www.ic.nhs.uk/statistics-and-data-collections/workforce/nhs-staffnumbers/nhs-staff-2000-2010-medical-and-dental. [Accessed 27 July 2011].

26 British Medical Association. Religion in Medicine. London: British Medical Association, 2007. www.bma.org.uk/equality_diversity/ religion_belief/religmedoct07.jsp [Accessed 27 July 2011].

27 Dyer C. GP accused of 'pushing religion' on patient opts for full GMC hearing. BMJ 2011;342:d3275

Address for correspondence: Dr Suzie Pomfret, Imperial College Healthcare NHS Trust, London W12 OHS, UK. Email: suzie_pomfret@hotmail.com 